\title{
Measurement of Organisation-Professional Conflict in the industrial psychology profession
}

\begin{abstract}
Authors:
Colette Lourens ${ }^{1}$

Leon J. van Vuuren ${ }^{1}$

Riëtte Eiselen ${ }^{1}$

Affiliations:

${ }^{1}$ Department of Industrial

Psychology and People

Management, University of

Johannesburg, South Africa

Correspondence to:

Colette Lourens

Email:

colettelourens@gmail.com

Postal address:

PO Box 524, Auckland Park

2006, South Africa

Dates:

Received: 25 Nov. 2011

Accepted: 07 Aug. 2012

Published: 09 Nov. 2012

How to cite this article: Lourens, C., Van Vuuren, L.J., \& Eiselen, R. (2012). Measurement of Organisation-Professional Conflict in the industrial psychology profession. SA Journal of Industrial Psychology/SA Tydskrif vir Bedryfsielkunde, 38(1), Art. \#1035, 12 pages. http:// dx.doi.org/10.4102/sajip. v38i1.1035
\end{abstract}

C 2012. The Authors. Licensee: AOSIS OpenJournals. This work is licensed under the Creative Commons Attribution License.
Orientation: Professionals, employed in organisations, operate within professional and organisational contexts serving different stakeholders. Subsequently, professionals may experience tension or conflict between their role as professional and employee.

Research purpose: To establish the measurement of the perceptions and experiences of industrial psychology (IP) professionals, employed in South African organisations, with regard to Organisation-Professional Conflict (OPC) as well as the antecedents associated with this phenomenon.

Motivation for the study: Although the extent to which professionals experience OPC is welldocumented for medical and accountancy professionals, the extent to which IP professionals experience this phenomenon remains unclear.

Research design, approach and method: A structured questionnaire was developed and applied as a cross-sectional survey to all registered South African IP professionals employed in organisations. Responses based on the $N=143$ self-selecting respondents were captured and utilised for statistical analysis.

Main findings: OPC in the IP profession can be considered as the incongruence between professional organisational roles and duties, and their responsibility to adhere to professional obligations. Professional autonomy and strategic alignment were found to mitigate the occurrence of OPC, whereas power tension and compromise of professionalism seem to exacerbate the occurrence thereof.

Practical/managerial implications: The research might create an awareness of the existence of OPC amongst the respective stakeholders. Knowledge of OPC may have implications for professionals who render their professional services to organisations.

Contribution/value-add: The findings may inform formal professional associations, industrial psychologists employed by organisations, their employing organisations, and the governing board, about the nature and extent of OPC.

\section{Introduction}

The efforts and roles of professionals are integral in contributing to society and the general wellbeing of the diverse stakeholder groups, to whom they provide their services, and to whom they are accountable. The requirements for an occupation to be afforded 'profession' status, as broadly stipulated in Peel (2005), include receiving specialised training with regard to theoretical and practical knowledge of the particular field, and providing specialised services to society in an attempt to enhance its wellbeing. Members of professions, or professionals, are usually required to be registered and licensed with an accreditation board or licensing board.

Professional membership inter alia implies complying with the prescribed codes of ethics, standards and norms for best practice of the profession (Higgs-Kleyn \& Kapelianis, 1999; Mannheim, 1981; Shafer, 2009) and promoting the delivery of effective and efficient professional services. Although professionals have professional autonomy within their fields of expertise, they are accountable for their professional actions to various stakeholder groups. These include the professional board or accreditation board, clients, fellow professionals, employing organisations, role players from government, the legislator, as well as society at large (Higgs-Kleyn \& Kapelianis, 1999; Jespersen, Nielsen \& Sognstrup, 2002; Sehested, 2002).

Professionals employed in organisations are required to operate within both professional and organisational contexts. In these respective contexts the professional serves different stakeholders and needs to remain cognisant of diverse contextual demands (Frankel, 1989; Peel, 2005; Pettifor, Sinclair \& Strong, 2005). Within the employing organisation, professionals are required to provide expert knowledge and advice to support the organisation, or to empower 
the organisation by providing the skills necessary to achieve set goals in an effort to enhance the organisation's wellbeing (Alexandra \& Miller, 2003). Organisations, in turn, are expected to afford professionals who are held accountable by professional boards, associations and colleagues to maintain professionalism, operate with sufficient autonomy and who have the independence to perform their role in accordance with set professional standards and norms (Bowen, Pearl \& Akintoye, 2007; Gendron, Suddaby \& Lam, 2006; HiggsKleyn \& Kapelianis, 1999; Voskuijl \& Evers, 2007).

The employing organisations may, however, promote values and have expectations of the professionals' services that are not aligned with the values and best practice norms and standards of the professional board to which the professional belongs (Alexandra \& Miller, 2003; Billings, 1981). Procedural bureaucracy of organisations, for example, may impede the professional's autonomy and independence. This misalignment of values and conflicting expectations may result in a conflict of interest, between professional obligations and organisational expectations, causing tension between professionals and this stakeholder group (Brandsen, 2009; Yu, Lee \& Lee, 2007). Finley, Mueller and Gurney (2004) note that the misalignment of mutual expectations or rather, Organisation-Professional Conflict (OPC), is not a recent phenomenon. It appears to have been a challenge for professionals since organisations started utilising the services of professionals.

OPC can be defined as the conflict that occurs when the expectations of and demands made on professionals, by their employing organisation, are in opposition to their professional obligations (derived from Alexandra \& Miller, 2003; Banks, 2006; Bowen et al. 2006; Brandsen, 2009; Gendron et al. 2006; Gunz \& Gunz, 2008; Keith-Spiegel \& Koocher, 1985; Yu et al., 2007). Although various professions differ in terms of their subject matter, previous research on the nature and extent of OPC has shown that the predominant factors contributing to OPC are similar. Power tensions between the bureaucratic and hierarchical organisational structures and the need of professionals for autonomy and independence, seem to be the leading causes of conflict (Brandsen, 2009; Gamage, 2006; Gunz \& Gunz, 2008; Shafer, 2002; Shafer, Park \& Liao, 2002). There is, however, a paucity of research on the phenomenon of OPC. This phenomenon has largely been explored amongst medical and accountancy professionals (Shafer, 2009), but the extent to which Industrial Psychologists as professionals experience this phenomenon remains unclear.

Not only is there a paucity of studies related to the existence of OPC within a profession, but measurement of OPC has also received little attention in the associated literature. In research conducted by Shafer et al. (2002), the authors aimed to assess OPC and professionalism in general by utilising the Halls Professionalism Scale. Their research focused on the behavioural implication of OPC on professionalism. The measurement instrument accounted for five characteristics of professionals, these being:
- professional community affiliation

- social obligation

- belief in self-regulation

- professional dedication

- autonomy demands.

The aim of this article is to report on an instrument that has been developed for the measurement of OPC, within the IP profession in particular, and to report on the antecedents of OPC and the extent to which members of the profession are exposed to OPC within their employing organisations.

\section{Organisation-Professional Conflict}

Professionals are expected to uphold professional behaviours in accordance with codes of ethics and practices (KeithSpiegel \& Koocher, 1985). In this instance, professional behaviour implies, theoretically at a minimum, selflessly working towards uplifting the wellbeing of stakeholders, as well as managing available resources whilst performing professional 'acts' and rendering services. Gunz and Gunz (2008) suggest that organisations may be opposed to the conservative and restricted nature of professional practices, believing that their standards and approaches may inhibit or restrict organisational growth and advancement. As a result, organisations may resist the requirements of professional regulatory boards that advocate professional autonomy and independence in their members. In this context professional autonomy generally entails the opportunity for professionals to make independent decisions and judgements, free from organisational influence (Shafer et al., 2002). For this reason, organisations often tend to exclude professionals from strategic decision-making processes. Consequently, professionals may sometimes be averse to authority, rules, regulations and procedures imposed by the organisation (Gamage, 2006). In opposition to professional regulatory boards and their requirements, professionals may need to yield to the governance of organisational demands and strict control over practices and activities in which professionals engage.

Professionals and their employers may sometimes be strategically misaligned in terms of the goals, values and intent fostered and pursued by the professional and the organisation respectively (Bowen et al., 2007; Gamage, 2006; Shafer et al., 2002). There appears to be a distinctly different focus in the goals of the professional and that of the employing organisation as a result of differences in what society, stakeholders and the organisation regard as important determinants of their respective goals (Brooks, 2001). This reiterates the predicament in which professionals find themselves, when they have to perform multiple roles in organisations in order to adhere to the diverse, even opposing, demands of multiple stakeholders (Gunz \& Gunz, 2008). This may differ across professions; for example, accountants' goals supposedly uphold and protect the interests of society, whereas lawyers' goals intend to support and protect the organisation or client regardless of their convictions (Gunz \& Gunz, 2008). 
Professionals who appropriate the business mindsets of an organisation, are less likely to experience OPC (Brierley \& Cowton, 2000; Gunz \& Gunz, 2008). Professionals conform to organisational cultures and align with organisational goals and values with little hesitation. Professionals with a predominantly external professional orientation may, however, be more likely to experience OPC as they abide strictly to professional standards and defy any opposing goals, values or standards of conduct. Shafer et al. (2002) suggest that the experience of OPC may reduce the organisational commitment of professionals, and consequently increase their intentions to resign.

Shafer et al. (2002) assessed OPC and professionalism in general by utilising the Hall's Professionalism Scale (HPS). The research focused on the behavioural implication of OPC on professionalism. The HPS measures five characteristics of professionals:

- professional community affiliation

- social obligation

- belief in self-regulation

- professional dedication

- autonomy demands.

Shafer et al. (2002) included additional questions that address the conflict between professional accounting standards and organisational objectives.

In terms of profiling professionals who may experience OPC, Shafer et al. (2002) found few, if any, differences in the experience of OPC across gender, age, qualification and years of experience of respondents. Differences were only identified regarding various industries, organisational size and the positions professionals occupy in organisations. In the study on accountants in the United Kingdom, professionals working in government sectors were generally more prone to experience high levels of OPC (Shafer et al., 2002). Finley et al. (2004) and Shafer et al. (2002) found a positive correlation between the experience of OPC and the size of organisations. Evidently, as an organisation's size increases, its structure becomes more formalised, therefore reducing professional autonomy. Organisational demands may compel professionals to conform at the expense of professional standards, goals and values, whilst professionals tend to be excluded from decision-making processes. Lastly, Shafer et al. (2002) suggest that professionals increasingly align with organisational goals and values as they advance in their careers. Professional values and goals might, thus, be increasingly negated as professionals ascend the corporate ladder.

\section{Manifestations of Organisation-Professional Conflict}

Professionals working as full-time employees, providing their professional services to a single organisation, rely on the organisation for their income. Professionals may be required to align themselves with organisational goals in return, thus distancing their practice from set professional objectives and forfeiting professional objectivity (Keith-
Spiegel \& Koocher, 1985; Siu \& Lam, 2009). Both Voskuijl and Evers (2007, p. 285), and Borden and Pritchard (2001, p. 81) depict the professional's predicament in referring to the expression 'he who pays the piper calls the tune'. This may hinder the ability of the professional to successfully balance multiple responsibilities and obligations, as the employing organisation expects the professional's undivided loyalty.

Professional values serve as measures to ensure the professional's work is of the highest standard (Bowen et al., 2007; Frankel, 1989; Harshman, Gulsinan, Fisher \& Yeager, 2005). In the accountancy, engineering and legal professions, the values of independence and objectivity are often countermanded by increased commercial greed. Confidentiality is another example of such a value that is believed to cause OPC in the accounting and legal profession (Brooks, 2001). Higgs-Kleyn and Kapelianis (1999) provide the example where professionals are faced with the predicament of deciding whether to maintain confidentiality or to report misrepresented information and expose unethical behaviour. Professionals are thus faced with the ethical dilemma of abiding by the demands of their employing organisation or to uphold their respective profession and its professional standards, where either option has undesirable consequences for the career of the professionals and for adherence to their professional obligations (e.g. maintaining confidentiality).

\section{Organisation-Professional Conflict in industrial psychology}

Based on work of Kornhauser and Hughes (as cited in Lefkowitz, 2003) the field of IP is regarded as a profession. The professional role of psychologists employed by organisations is also circumscribed by the Professional Board of Psychology of the Health Professions Council of South Africa (HPCSA). Psychologists in general need to regulate their professional practice in terms of the professional behaviour stipulated by the board. Subsequently, it could be assumed that its practitioners may also experience OPC. Literature, or alternative evidence, is limited, which is intended to ascertain whether or not this is true for industrial psychologists working in organisations, nor has any measure been developed to assess OPC amongst practitioners.

Kornhauser and Hughes' (as cited in Lefkowitz, 2003) suggest possible antecedents for the phenomenon of OPC relevant in the profession of IP. These include a discrepancy between professional and organisational goals and values, as well as bureaucratic organisational control and influence on the independent work and autonomous decision making of professionals. Should the professional blindly foster greater loyalty towards the employing organisation? If this is done, then the tension is alleviated and the manifestations of OPC are mitigated whilst professionalism in IP is compromised (Lefkowitz, 2003).

The professional objectives and standards of industrial psychologists may not necessarily be congruent with the organisational culture (Lefkowitz, 2003; Van Vuuren, 2006). Industrial psychologists focus primarily on ensuring 
that the interests of employees are accounted for in the organisational design and structures, whilst organisations primarily demand that new developments and initiatives ensure productivity and financial success (Lefkowitz, 2003). Strategic misalignment is prevalent and occurs when professionals' adhere to organisational demands and conform to organisational structures. This occurs to the detriment of professionalism.

As a second point, industrial psychologists are employed within organisations where they may fall prey to authoritarian managers (Lefkowitz, 2003; Van Vuuren, 2006). In stripping professionals of their autonomy and independence, industrial psychologists may be excluded from key decisions where they could have made significant and valuable contributions (Lefkowitz, 2003). Employers establish how and where professionals make contributions and exercise influence, thus denying them exposure to information crucial for future decision making. A concern here is that industrial psychologists may be immersed in the organisational culture ('the way of doing things around here') in a subtle way (Van Vuuren, 2006). As such, they may not even be consciously aware of their conformance.

Kornhauser and Hughes (as cited in Lefkowitz, 2003) along with Van Vuuren (2006), note that similar to other professions, industrial psychologists serve and are required to balance the needs of multiple stakeholders. OPC becomes inevitable as the industrial psychologist is sometimes obliged to yield to the needs of one dominant stakeholder, which consequently negates or disregards the legitimate requirements of another stakeholder.

In conclusion, from the literature reviewed in this section, it is assumed that the most common antecedents of OPC in the IP profession are:

- power tensions originating from organisational bureaucracy and hierarchy, and professional autonomy and independence

- strategic misalignment as a result of opposing organisational and professional goals and values

- conflicting roles when satisfying multiple stakeholders

- the strength of the professional's respective organisational and professional commitments

- adherence to professional codes of conduct and ethics within an unscrupulous organisation and

- organisational cultures that endorse dubious and deviant behaviours.

Whilst scholars have defined and acknowledged the existence of the OPC predicament that professionals are faced with, few have reported on the specific nature thereof (Shafer et al., 2002). The phenomenon of OPC has been reported to exist within a wide range of professional fields, including the engineering, legal and accountancy fraternities as referred to previously. However, whether or not this phenomenon exists within the professional field of IP remains unexplored, and additionally the means of measuring the extent to which it is experienced also remains unexplored and conflicting views prevail (Kornhauser \& Hughes in Lefkowitz, 2003; Van Vuuren, 2006).

\section{Research design Research approach}

A quantitative research method, in the form of a crosssectional sample survey amongst psychologists either currently or previously employed in industry, was utilised. This provided the opportunity to explore the phenomenon of OPC via indirect observation in a relatively objective, valid and reliable manner (cf. Kerlinger \& Lee, 2000; KovacsBurns, 2005). As a result of the paucity of evidence regarding the existence and experience of OPC within the industrial psychology profession, this study is exploratory in nature (cf. Gravetter \& Forzano, 2009).

\section{Research method}

\section{Participants and procedure}

The target population for this study was defined as industrial psychologists in South Africa who were either employed at the time of the survey, or were previously employed by corporate organisations during their careers as practicing registered industrial psychologists. More specifically, industrial psychologists were targeted as the sample:

- who possessed a minimum of a master's degree qualification

- who were registered as psychologists with the Professional Board for Psychology of the HPCSA

- who had had more than one year of experience as practicing professionals.

In order to obtain the most comprehensive sampling frame of practicing industrial psychologists in South Africa, two lists were utilised: the list of all industrial psychologists registered with the HPCSA as well as the complete list of members of the Society for Industrial and Organisational Psychology of South Africa (SIOPSA). These are the most comprehensive lists of industrial psychologists in South Africa. Permission was obtained from both the HPCSA and SIOPSA to contact those whose names and contact details appeared on either one of these lists. Where duplication was evident, the name that appeared on the HPCSA database was removed. The contact details were supplied in the form of postal and email addresses respectively.

The research instrument was administered to all members in the sampling frame either electronically (web based survey) or by post (postal survey). This implies that a 100\% sample was selected. This strategy resulted in the distribution of the questionnaire to 3021 (770 postal and 2251 electronic) registered IP professionals. The cover letter invited IP professionals to voluntarily and anonymously participate in the survey, informed them of the aim of the study and assured them of the safeguarding and confidentiality of information provided.

As a result of the fact that responses were voluntary, the sample was self-selecting. A total of 185 responses were 
obtained (62 postal and 123 electronic). Of these, 171 respondents met all of the inclusion criteria of the study. As a result of the fact that those who omit a large number of items may compromise the validity of the results obtained, respondents who omitted more than one of the opinionrelated items were excluded. This yielded a total of 143 $(N=143)$ usable questionnaires.

\section{Measuring instrument}

The research instrument consisted of three sections consisting of either closed or open-ended questions. For the purposes of the research question addressed in this paper, only the results pertaining to section 1 and section 2 are utilised. Section 1 related to biographical and demographical information, that is: gender, age, ethnicity, level of education, number of years of experience in the profession, industry of practice, the size of the employing organisation and the field of practice and expertise.

In section 2, 29 items related to the antecedents of OPC were formulated. Fourteen of these 29 Likert-type items ranging from 1 ('never') to 6 ('very often') gauged the extent to which the goals and values of the employing organisation and the profession differed. Examples include:

'My professional responsibilities are aligned with the organisational expectations.' (Participant of study, industrial psychologist)

'My superiors expect me to act according to my professional values.' (Participant of study, industrial psychologist)

'I am expected to choose between adhering to professional standards and doing what is best for the organisation.' (Participant of study, industrial psychologist)

The remaining 15 Likert-type items ranging from 1 ('never') to 6 ('very often') measured the extent to which respondents experience professional autonomy and independence within their employing organisations. Examples include:

'I am free to act according to my professional judgement.' (Participant of study, industrial psychologist)

'I can act free from conflicts of interest that affect my professionalism.' (Participant of study, industrial psychologist)

'Organisational politics rather than professional judgement dictate decisions.' (Participant of study, industrial psychologist)

The items included in section 2 were based on the dimensions of OPC that emerged from the literature review. To establish the content validity of the measurement instrument, five experts within the field of IP, who were employed in organisations, were requested to evaluate the content of items to ensure that all items related to the issue of OPC.

\section{Statistical analysis}

The responses were captured and then statistically analysed utilising the statistical package, SPSS version 18 (SPSS, 2010). The data analysis included descriptive statistics of each item (question) by means of frequencies and percentages or means, standard deviations, skewness and kurtosis (where applicable). In order to reduce the dimensionality of the number of items in section 2, exploratory factor analysis (Principle Axis Factoring) using the latent root criterion of eigenvalues greater than one was used to identify the appropriate number of factors (Hair, Black, Babin, Anderson \& Tatham et al, 2006). A Varimax rotation assisted in the interpretation of the factors as orthogonality was assumed. Inferential statistical procedures, to compare the responses of the groups of respondents included chi-squared tests of independence, $t$-tests and ANOVAs.

\section{Research procedure}

The questionnaire was converted into a web-based electronic format using an open access platform. The functionality of the online version was evaluated and was found to be user friendly. Respondents gained access to the electronic version using a Uniform Resource Locator (URL) that allowed for anonymous submission of the completed questionnaire. The postal survey was mailed to the industrial psychologists on the HPCSA's address list with the request to return it anonymously to the researchers. Follow up emails and letters were sent two weeks after the initial distribution in an attempt to increase response rates. Confidentiality was ensured by storing responses in a secure location, whilst the principle of anonymity was maintained as respondents were not required to identify themselves in either the postal or electronic questionnaire (cf. Cooper \& Schindler, 2008; cf. Leedy \& Ormond, 2010).

\section{Results}

Table 1 provides a summary of the biographic and demographic particulars of the participants. The majority of the participants were female (59.4\%), Caucasian (88.8\%), at least 40 years of age $(51.1 \%)$, in possession of a master's degree $(84.6 \%)$ and had at least five years of work experience (73.5\%). The majority (58.0\%) of the respondents are currently in full-time employment at an organisation whilst the rest were previously employed at organisations. The diverse nature of the areas of practice, industries and positions held by the participants in the sample, is also evident from Table 1 .

Figure 1 visually represents the results related to the three items in section 3 of the questionnaire addressing the respondents' opinion and experience of OPC specifically: more than a third of the respondents $(37.8 \%)$ agreed or strongly agreed that they experience or have experienced OPC within their employing organisations. Similarly, 37.8\% agreed or strongly agreed that other industrial psychologists working in organisations experience OPC. On the question whether or not OPC is a phenomenon only experienced in professions other than IP, more than two-thirds of the respondents $(31.5 \%$ and $37.8 \%$ respectively) were either neutral or disagreed.

\section{Antecedents of Organisation-Professional Conflict}

In assessing the latent structure of the 29 items in section 2, related to measuring the antecedents of $\mathrm{OPC}$, an exploratory 
TABLE 1: Demographic profile of participant $(N=143)$.

\begin{tabular}{|c|c|c|}
\hline Demographic particulars & $\%$ of sample & Frequencies \\
\hline \multicolumn{3}{|l|}{ Gender } \\
\hline Female & 59.44 & 85 \\
\hline Male & 39.16 & 56 \\
\hline \multicolumn{3}{|l|}{ Ethnicity } \\
\hline Caucasian & 88.81 & 127 \\
\hline African, Indian or Coloured & 9.79 & 14 \\
\hline \multicolumn{3}{|l|}{ Age } \\
\hline$<40$ & 48.25 & 69 \\
\hline $40-49$ & 25.87 & 37 \\
\hline$>50$ & 25.17 & 36 \\
\hline \multicolumn{3}{|l|}{ Level of education } \\
\hline Master's degree & 84.62 & 121 \\
\hline Doctoral degree & 15.38 & 22 \\
\hline \multicolumn{3}{|l|}{ Years experience } \\
\hline$<5$ years & 26.57 & 38 \\
\hline $5-10$ years & 27.97 & 40 \\
\hline $10-20$ years & 27.27 & 39 \\
\hline$>20$ years & 18.18 & 26 \\
\hline \multicolumn{3}{|l|}{ Current employment status } \\
\hline Full-time at an academic institution & 6.99 & 10 \\
\hline Permanent full-time at an organisation & 58.04 & 83 \\
\hline Temporary employment at an organisation & 0.70 & 1 \\
\hline Contract appointment at an organisation & 3.50 & 5 \\
\hline Self-employed or In private practice & 24.48 & 35 \\
\hline Not employed (not seeking employment) & 0.70 & 1 \\
\hline Retired & 0.70 & 1 \\
\hline Other & 3.50 & 5 \\
\hline \multicolumn{3}{|l|}{ Main area of practice } \\
\hline Career and Occupational Wellbeing & 14.69 & 21 \\
\hline Human Resources (HR) and Personnel Management & 31.47 & 45 \\
\hline Industrial Psychology (IP) General & 11.19 & 16 \\
\hline Organisational and Management Psychology & 25.17 & 36 \\
\hline Psycho-legal & 4.20 & 6 \\
\hline Assessment & 27.97 & 40 \\
\hline Human Resource (HR) development & 16.78 & 24 \\
\hline Other & 1.40 & 2 \\
\hline \multicolumn{3}{|l|}{ Industries of practice at time of study } \\
\hline All or Consulting & 13.29 & 19 \\
\hline Engineering, Extractive industry and Energy & 15.38 & 22 \\
\hline Finances & 16.78 & 24 \\
\hline Information Technology & 3.50 & 5 \\
\hline Manufacturing & 3.50 & 5 \\
\hline Services & 20.28 & 29 \\
\hline Other & 9.09 & 13 \\
\hline \multicolumn{3}{|l|}{ Positions of respondents } \\
\hline HR General & 14.69 & 21 \\
\hline HR Specific & 6.29 & 9 \\
\hline IP General & 21.68 & 31 \\
\hline IP Specific & 14.69 & 21 \\
\hline Senior Management & 8.39 & 12 \\
\hline Executive Management & 12.59 & 18 \\
\hline Other & 6.29 & 9 \\
\hline
\end{tabular}

$N$, number.

Percentages do not total 100 as a result of missing values.

factor analysis was conducted. The sample size was considered sufficient: this amounted to a minimum of five cases for each item included in the analysis (Hair et al., 2006; Pallant, 2007). Departure from normality of each item was assessed prior to conducting the factor analysis, and the descriptive statistics of all items had small absolute skewness ( $\mid$ skewness $\mid<2$ ) and absolute kurtosis ( $\mid$ kurtosis $\mid<8$ ) (Hair et al., 2006).

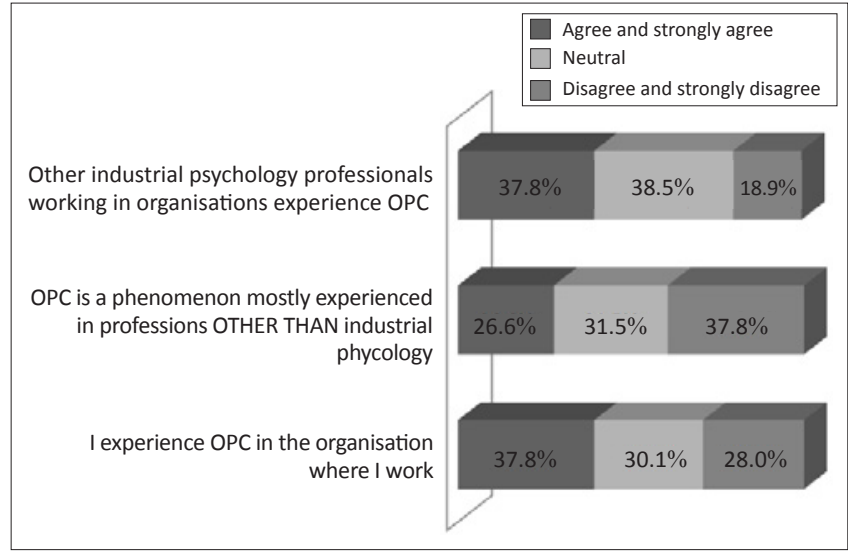

FIGURE 1: Respondents' experiences and perceptions of the existence of Organisation-Professional Conflict (OPC).

To assess whether or not a factor analysis of the items was feasible, Bartlett's test of sphericity was conducted and was found to be significant $\left(\chi^{2}(378)=2913.95, p<.005\right)$ whilst the Kaiser-Meyer-Olkin measure of sampling adequacy was larger than .6 $($ KMO $=.943)$ as specified in Pallant (2007). Each item, except one, had a measure of sampling adequacy (MSA) greater than .6 (cf. Hair et al., 2006), and therefore shared sufficient correlation with at least one other item to be retained in the factor analysis. Item 9 ('Employees rely primarily on organisational rules and procedures to guide their practices.') was the only exception with an MSA of less than 0.6. Whilst the 29 items generally pertained to the respondents' personal experiences in their organisations, item 9 related more to the respondents' perceptions of other organisational practices and was not retained for the factor analysis. Lastly, the extracted communalities of all remaining 28 items in the factor analysis exceeded 0.3 (Hair et al., 2006; Pallant, 2007). Considering these indicators, there was insufficient correlation and common variances between the remaining 28 items to warrant a factor analysis.

The exploratory factor analysis was conducted utilising common factor analysis (Principle Axis Factoring) with a Varimax rotation to ease interpretation (Hair et al., 2006; Kahn, 2006; Kerlinger \& Lee, 2000; Pallant, 2007). Four factors were extracted based on the latent root criterion of eigenvalues greater than one. The four factor structure accounted for $66.95 \%$ of the total variance in the 28 items included in the factor analysis. In Table 2, the number of items constituting each factor, sample items and the reliability (Cronbach alpha) of each factor are displayed. The internal reliability of each factor exceeded the cut-off point of 0.7 and, hence, each factor is considered reliable (Hair et al., 2006; Pallant, 2007). The wording of items with high loadings on factors were assessed and subsequently an appropriate factor name was assigned to each factor (Table 2).

Strategic Alignment (Factor 1) focuses on the industrial psychologist's professional Strategic Alignment with that of the organisation. This relates to whether or not the professional's obligations, values, goals, contributions and decisions are aligned to or in conflict with that of the employing organisation. Items loading on this factor 
TABLE 2: Description of factors.

\begin{tabular}{|c|c|c|c|c|c|c|c|c|}
\hline Factor number & $\begin{array}{l}\text { Number of } \\
\text { items }\end{array}$ & Sample items & $\begin{array}{l}\text { Cronbach Alpha } \\
\text { value }(\alpha)\end{array}$ & Factor name & Minimum & Maximum & $M$ & SD \\
\hline 1 & 14 & $\begin{array}{l}\text { My professional responsibilities are aligned with the } \\
\text { organisational expectations } \\
\text { My superiors expect me to act according to my professional values } \\
\text { I am granted sufficient access to information relevant to key } \\
\text { decisions related to my work as industrial psychologist } \\
\text { I can act free from conflict of interests that affect my profession }\end{array}$ & 0.959 & $\begin{array}{l}\text { Strategic } \\
\text { Alignment }\end{array}$ & 1.43 & 6.00 & 4.43 & 1.07 \\
\hline 2 & 7 & $\begin{array}{l}\text { Organisational politics rather than professional judgement } \\
\text { dictate decisions } \\
\text { I am expected to follow organisational rules and procedures } \\
\text { even if it goes against my professional judgement } \\
\text { My decisions as an industrial psychology professional are overruled } \\
\text { Decisions taken by my superiors go against my judgement as a } \\
\text { professional industrial psychologist }\end{array}$ & 0.893 & Power Tension & 1.00 & 5.71 & 2.80 & 1.13 \\
\hline 3 & 3 & $\begin{array}{l}\text { My professional code is compromised by decisions taken } \\
\text { by my superior } \\
\text { I am expected to choose between adhering to professional } \\
\text { standards and doing what is best for the organisation } \\
\text { I am expected to protect the interests of the organisation } \\
\text { where I work even if it goes against the interest of its } \\
\text { employees }\end{array}$ & 0.809 & $\begin{array}{l}\text { Compromise of } \\
\text { Professionalism }\end{array}$ & 1.00 & 6.00 & 2.81 & 1.24 \\
\hline
\end{tabular}

$M$, mean; SD, standard deviation.

included: 'Decisions taken by my superiors are aligned with the conduct expected of me as an industrial psychology professional' and 'My superiors/management rely on my professional opinion to inform their decisions and practice'. A score of one indicates that the respondent experiences no strategic alignment whilst a score of six indicates a great deal of strategic alignment between the profession and the organisation. The higher the score on this factor, the greater is the experience of Strategic Alignment.

Power Tension (Factor 2) generally pertains to the challenges industrial psychologists experience in affecting their professional judgement in bureaucratic and controlling organisations. This reflects the extent to which respondents experience their professional judgement being defied by the management of the organisation, and their need to condone organisational business practices that do not carry their professional approval. Items loading on this factor included: 'Organisational politics rather than professional judgement dictate decisions' and 'Decisions taken by my superiors go against my judgement as professional industrial psychologist'. For this factor a score of one indicates that there is no Power Tension whilst a score of six indicates a great deal of tension. In this case, a lower score is associated with less tension experienced and vice versa.

Compromise of Professionalism (Factor 3) relates to the disjunctive expectations of the profession and employing organisations, which causes industrial psychologists to feel pressurised and to conform to organisational demands (i.e. organisational rules, policies and guidelines) at the expense of their profession. Items loading on this factor included: 'My professional code is compromised by decisions taken by superiors' and 'I am expected to choose between adhering to professional standards and doing what is best for the organisation'. For this factor, a score of one signifies that the respondent experiences no conflict, whereas a score of six signifies that the respondent experiences a great deal of pressure to compromise their professionalism.

Professional Autonomy (Factor 4) refers to the professional autonomy, involvement and influence of industrial psychologists (i.e. the extent to which their recommendations are utilised) during decision-making processes regarding industrial psychological matters in the organisation. This includes the autonomy professionals are granted to make judgements independent of management. Two of the items in this factor had high negative loadings and were reversed. The items are: 'Final decisions regarding employees are made irrespective of my recommendations as a professional' and 'In situations relating to decisions of a professional nature, I need authorisation from superiors'. A score of one on this factor is indicative of an inhibited level of Professional Autonomy whereas a score of six indicates that respondents experience a great deal of autonomy.

For each respondent, the average over all the items in each of the factors was calculated to yield a factor 'score'. Although individual scores on the factors ranged from very low to very high values (Table 2), Strategic Alignment had the highest mean score on average $(\mathrm{M}=4.43, \mathrm{SD}=1.07)$, followed by Professional Autonomy $(\mathrm{M}=3.69, \mathrm{SD}=1.08)$. This suggests that respondents, on average, seem to experience that their professional and organisational goals and values are aligned, and that they are granted the necessary independence to make decisions and act on their professional judgement. Power Tension $(\mathrm{M}=2.79, \mathrm{SD}=1.13)$ and Compromise of Professionalism $(\mathrm{M}=2.81, \mathrm{SD}=1.24)$ had the lowest mean scores, suggesting that on average there is limited Power Tension and need to compromise professionalism amongst the respondents.

All of the factors were statistically significantly correlated with one another (Pearson product-moment correlations). 
The absolute value of the lowest correlation is .46 whilst the maximum absolute value is .72 (Table 3). The results suggest that the higher the experience of Strategic Alignment, the lower Power Tension $(r=-.72)$ and Compromise of Professionalism $(r=-.59)$ become, whilst Professional Autonomy $(r=.71)$ tends to be higher. High levels of Power Tension are associated with low levels of Professional Autonomy $(r=-.6)$ and with high levels of Compromise of Professionalism $(r=.63)$. Lastly, high levels of Compromise of Professionalism is associated with lower levels of Professional Autonomy $(r=-.46)$. From the correlations and their directions it, thus, seems that those industrial psychologists in organisations that have Professional Autonomy, and an alignment between professional and organisational goals and values (Strategic Alignment), are likely to experience less Power Tension and Compromise of Professionalism. The contrary is also true.

The factors were subsequently correlated with the single item related to personal experience of OPC. As a result of the fact that this single self-report item was measured on an ordinal scale, Kendall's Tau $(\tau)$ was used as a measure of the association of these items with each of the four factors, and the results are displayed in Table 4 .

Although the magnitude of the relationship was small, each of the factors, except Professional Autonomy, correlated significantly with the self-report item. The experience of OPC is negatively correlated with Strategic Alignment $(\tau=-.17)$ implying that the more Strategic Alignment is experienced, the less likely the person is to report experiencing OPC. In contrast, the more Power Tension $(\tau=.22)$ and Compromise of Professionalism $(\tau=-.16)$ are evident, the more likely the person is to report experiencing OPC. The practical significance of these findings is, however, limited.

\begin{tabular}{|c|c|c|c|}
\hline Factors & Power Tension & $\begin{array}{l}\text { Compromise of } \\
\text { Professionalism }\end{array}$ & $\begin{array}{l}\text { Professional } \\
\text { Autonomy }\end{array}$ \\
\hline \multicolumn{4}{|l|}{ Strategic Alignment } \\
\hline Pearson correlation & -.72 & -.59 & .71 \\
\hline$p$-value & $<.005$ & $<.005$ & $<.005$ \\
\hline \multicolumn{4}{|l|}{ Power Tension } \\
\hline Pearson correlation & - & .63 & -.60 \\
\hline$p$-value & - & $<.005$ & $<.005$ \\
\hline \multicolumn{4}{|c|}{ Compromise of Professionalism } \\
\hline Pearson correlation & - & - & -.46 \\
\hline$p$-value & - & - & $<.005$ \\
\hline
\end{tabular}

$p$, probability.

TABLE 4: Correlations of factors with the single self-report item utilising Kendall's $\tau$.

\begin{tabular}{ll}
\hline Factors & I experience OPC in the organisation where I work \\
\hline $\begin{array}{l}\text { Strategic Alignment } \\
\text { Kendall's } \tau\end{array}$ & -.17 \\
$p$-value & $.007<.05$ \\
Power Tension & .22 \\
Kendall's $\tau$ & $.001<.05$ \\
$p$-value & \\
Compromise of Professionalism & .16 \\
Kendall's $\tau$ & $.015<.05$ \\
$p$-value & \\
Professional Autonomy & -.12 \\
Kendall's $\tau$ & .060 \\
$p$-value &
\end{tabular}

OPC, Organisation-Professional Conflict; $p$, probability.

\section{The extent to which Organisation-Professional Conflict is experienced: Biographical and background differences}

In ascertaining whether or not respondents from different biographical groups, or groups of respondents from different backgrounds, experience similar levels of OPC, the following items were utilised:

- The item relating to the respondents' self-report of their experience of the phenomenon ('I experience OPC in the organisation where I work.')

- The item relating to the four extracted factors (Strategic Alignment, Professional Autonomy, Compromise of Professionalism and Power Tension).

Certain categories of the biographical and background questions of respondents were combined as a result of the small number of cases within some of the categories. This facilitated meaningful comparison and interpretation of results. Categories relating to age groups, size of the organisation, position and industry variables were combined.

Furthermore, only respondents who were in permanent full-time employment at an organisation, or who were selfemployed or in private practice were compared in terms of their experience of OPC. Similarly, in comparing the various fields of expertise of the respondents, the four most prevalent fields were compared. These fields were:

- organisational and management psychology

- human resource (HR) management

- assessment

- human resource development.

Only the biographical dimensions, where differences prevailed, are discussed.

There was a statistically significant difference between respondents in possession of master's and doctoral degrees in terms of their mean experience of Compromise of Professionalism $(t(39,29)=-3.38, p=.002<.05)$. Based on the observed means, employees with doctoral degrees on average experience less Compromise of Professionalism than employees with master's degrees. The mean of at least one age group differed significantly from the others with regard to the Power Tension dimension $(F(3,138)=4.51$, $p$-value $=.005<.05)$. The post-hoc test (Scheffe) did not reveal which specific groups differ statistically but based on the observed means, those in the age group of 50 or older have experienced the most Power Tension on average. The population means in terms of Strategic Alignment $(F(3,139)=3.24, p=.024<.05)$ and Professional Autonomy $(F(3,139)=5.07, p=.002<.05)$ showed statistically significant differences. Post-hoc tests (Scheffe) suggest respondents with more than five years but less than ten years of experience, perceived less Strategic Alignment in organisations, than respondents with 20 years or more experience. Respondents with 10 or less years of experience also experienced less Professional Autonomy than their counterparts with 20 or more years of experience. In terms of employment status and the self-report item reflecting their experience of OPC, the chi-square test of independence was rejected $\left(\chi^{2}(2)=6.434\right.$, 
$p=.039<.05)$. Respondents in private practice or who are selfemployed are less likely to experience (strongly disagree or disagree) OPC in their work than those in other employment categories.

Based on ANOVA tests, statistically significant differences between population means were evident for Strategic Alignment $(F(5,115)=2.56, p=.31<.05)$ and Professional Autonomy $(F(5,115)=3.69, p=.004<.05)$ in relation to the positions of respondents in their organisations. The posthoc tests (Scheffe) could not detect the nature of differences between groups in terms of Strategic Alignment, but the observed means allude to the possibility that respondents in executive management experience more Strategic Alignment. In terms of Professional Autonomy, the Dunnett T3's post-hoc tests revealed that respondents in general HR, HR specific and IP specific positions tend to experience less Professional Autonomy on average than those in Executive management.

There were statistically significant differences between respondents from different industries in terms of their experience of Strategic Alignment $(F(4,112)=5.04$, $p=.001<.05)$, Power Tension $(F(4,112)=3.13$, $p=.018<.05)$ and Professional Autonomy $(F(4,112)=4.99$, $p=.002<.005)$. Based on Scheffe's post-hoc tests those in education and government organisations (categorised as Other) experience significantly less Strategic Alignment, on average, than those in each of the other specified industries. These respondents (employed in education and government) on average experience more Power Tension than respondents working in consulting, finances or engineering, the extractive industry and energy. Respondents in education and government on average also seem to experience less Professional Autonomy than their counterparts in the financial, services, consulting or all industries.

Comparisons made between respondents in a specific field, and those who do not practise in that particular field, revealed that respondents actively involved in HR and Personnel Management experience, statistically, significantly more Professional Autonomy $(t(109,79)=-2.233, p=.028<.05)$ than those not practicing in HR and Personnel Management.

\section{Discussion}

Various authors have reported that OPC is a phenomenon that is generally experienced amongst professionals (Barry \& Ohland, 2009; Bowen et al., 2007; Brierley \& Cowton, 2000; Gendron et al., 2006; Gunz \& Gunz, 2008; Higgs-Kleyn \& Kapelianis, 1999; Shafer, 2002; Shafer, 2009; Shafer et al., 2002). The aim of this article was to report on an instrument that has been developed for the measurement of OPC within the IP profession in particular. Furthermore, the aim was to ascertain the perceptions and experiences of OPC amongst IP professionals employed in South African organisations, and establish possible antecedents of the phenomenon. From the findings in this study it seems that power dynamics in bureaucratic and authoritative organisational cultures may be associated with the experience of OPC (Gamage,
2006; Harries-Jenkins, 1970; Shafer et al., 2002). Strategic misalignment of professional and organisational values and goals may further exacerbate the occurrence of the phenomenon (Bowen et al, 2007; Gunz et al, 2009). In addition, it seems that a lack of professional independence and limited involvement, in key decisions relating to the respective professionals' areas of expertise, may often necessitate that professionals compromise their professionalism (Banks, 2006; Brandsen, 2009; Gunz \& Gunz, 2008).

The findings in this study were aligned to the findings of research in other professions. Particularly, OPC is a phenomenon that is not limited to professions other than the IP profession. More than a third (37.8\%) of the respondents indicated that they experience OPC, confirming Van Vuuren's (2006), and Kornhauser and Hughes' (in Lefkowitz, 2003) assumption that industrial psychologists do indeed experience OPC.

Four factors that generally contribute to the experience of OPC amongst IP professionals in South African organisations were identified: Strategic Alignment, Power Tension, Compromise of Professionalism and Professional Autonomy. These are in line with the influencing dynamics established in the literature of others professions. Both Strategic Alignment and Professional Autonomy were found to reduce the possibility of experiencing OPC (positive factors), whilst Power Tension and Compromise of Professionalism were found to be associated with experiencing OPC. Figure $2 a$ and Figure $2 b$ illustrate the dynamic relationship of the four factors (i.e. antecedents) with the experience of OPC. The vertical axes in these figures represent the intensity to which each of the two positive and negative factors are experienced, whilst the respective two shaded areas represent the existence or absence of OPC in each instance. An explanation of the figures follows.

The results indicated that professionals experiencing little or no strategic alignment and professional autonomy (A) tended to report higher levels of power tension and the need to compromise their professionalism (B) (refer to Figure 2a). This relationship between the factors was associated with a greater likelihood of respondents experiencing OPC (C) in their specific employing organisations. In reference to Figure $2 b$, professionals experiencing strategic alignment and professional autonomy (A) may experience less power tension, and would be less prone to compromising their professionalism (B) in their employing organisation. Consequently, these professionals may be less likely to experience OPC (D). From the evidence gathered, respondents in this study seemed to experience limited OPC as they generally reported to have high levels of Strategic Alignment and Professional Autonomy.

Few differences exist between the experiences of OPC by IP professionals in terms of their biographical and contextual background (Shafer et al., 2002). Respondents who have obtained doctoral degrees may experience less need to compromise their professionalism as they enjoy more status 


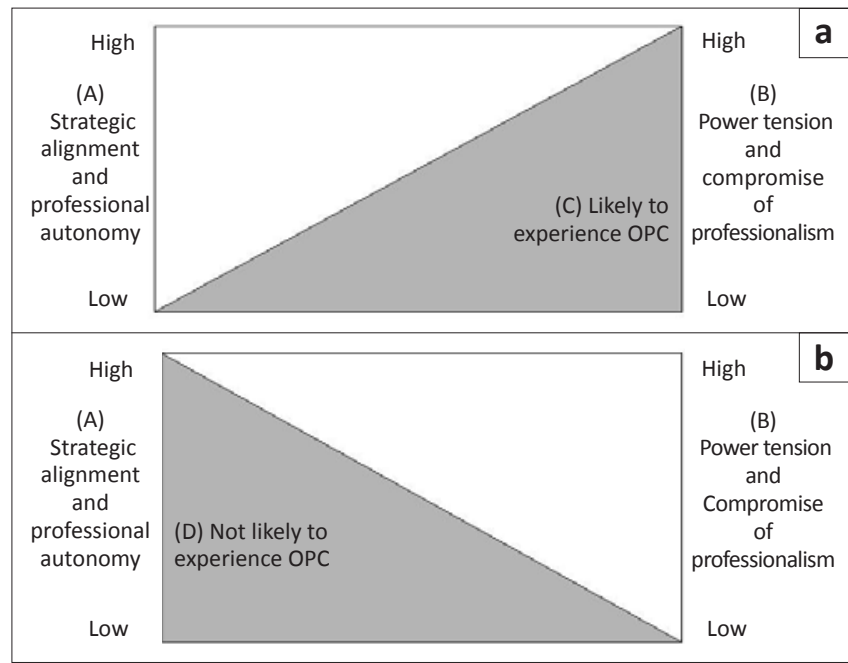

FIGURE 2: (a) Likely to experience Organisation-Professional Conflict (OPC): Power Tension and Compromise of Professionalism high. (b) Not likely to experience Organisation-Professional Conflict (OPC): Strategic Alignment and Professional Autonomy high.

and respect in their organisation. Respondents 50 years of age and older generally have more extensive experience in the industry and may thus experience more power tension than younger respondents. Organisations might enforce stricter regulatory measures upon professionals who have less than ten years' experience. Therefore, they experience less strategic alignment and professional autonomy.

When professionals hold more senior positions, and are involved in key decisions, their business values and goals may change at the cost of their professionalism (Shafer et al., 2002); thus, executive managers may experience more strategic alignment and professional autonomy. Similar to the experience of UK accountants employed in government (Shafer et al., 2002), respondents working for the South African government (other organisations) were found to experience less professional autonomy and, subsequently, more power tension. Government organisations are often hierarchically and bureaucratically structured, requiring individuals to adhere and conform to established protocols. Governmental institutions tend to have different values and goals to contemporary corporate organisations. Professional services of these institutions could differ from traditional expectations, accounting for the lack of strategic alignment experienced by these respondents. Contrary to Shafer et al.'s (2002) finding relating to the occurrence of OPC as a function of the size of organisations, no significant differences were found in this study.

Respondents in Human Resource (HR) and Personnel Management positions were found to experience more professional autonomy. Industrial psychologists often fulfil general human resource (HR) functions in the HR departments of organisations. This entails various $H R$ and personnel management practices such as recruitment, selection, succession planning, talent management and employment (labour) relations which are often regarded as specialist fields. Their contributions might be more highly regarded by superiors, affording these professionals influence in making decisions and judgements. Although there were slight differences in terms of the respondents' biographical and contextual backgrounds, these were of minor proportion and little significance. OPC could thus be experienced by IP professionals working in diverse work environments where they assume various roles and fulfil the diverse needs of stakeholders.

OPC can be considered as the incongruence that may be experienced between the professional's organisational role and duties, and that of the role as professional with professional obligations. Professionals provide services to multiple stakeholders and are, thus, challenged in balancing their roles as professionals and employees of an organisation. This phenomenon may be quantitatively measured by means of a questionnaire. From the responses to the questionnaire it seems that IP professionals are just as likely to experience the phenomenon as any other profession. Similar to the experience in other professions, the experience of this 'role incongruence' may be ascribed to power tensions between the levels of management and their expectations that could result in professionals compromising their professionalism (i.e. professional standards and values). These antecedents may exacerbate a misalignment of strategic values and goals of the organisation and profession, and 'strip' professionals of their autonomy and independence in their professional practices in the organisation. The study provides evidence that industrial psychologists are likely to experience OPC irrespective of their biographical or background characteristics (i.e. age, gender, level of qualification, years of experience, field of expertise, position and industry).

\section{Limitations of the study}

The sampling frame, although the most appropriate, may have excluded members of the target population. The response rate was very low and the sample size thus reasonably small. The research instrument relied on the selfreport of the respondents at a specific point in time and could have possibly elicited socially desirable responses, thus, limiting the generalisability (small sample size) and relevancy (socially desirable responses) of the results. As a result of the paucity of previous research there were no comparable South African studies. This study only focused on IP professionals in full-time employment by organisations. The experience of professionals in academia and those practicing as external consultants were not investigated and, thus, cannot be commented on.

\section{Recommendations}

OPC is not a well-researched topic within the profession of IP and many areas for possible research still exist. Future research could consider the impact that organisational contexts and culture (especially relating to their ethical conduct) have on the experience of the phenomenon. In addition possible avenues for research are presented by the following:

- the emotional dynamics that underpin the phenomenon

- the influence of job satisfaction 
- professional dedication

- organisation-professional commitment and loyalty on the occurrence of OPC.

The involvement of professionals with formal associations and continuous professional development initiatives on the dynamics of OPC may also be considered. Considering that the antecedents of OPC are similar across professions, the questionnaire utilised in this research study could be further modified, refined and developed towards the generic measurement of OPC across various professions. Qualitative research methods such as interviews, narratives and focus groups could be considered as alternative means to obtain more contextual and personal data, to identify more subtle nuances underlying the dynamics of the phenomenon.

IP could be described as an evolving profession that may not yet have come to terms with the challenges other professions may already have anticipated or dealt with. The findings of the research may, thus, inform the profession (i.e. formal professional associations), practicing industrial psychologists employed by organisations, their employing organisations, and the governing board of the profession, about the nature and extent of OPC and the need to account for this phenomenon in all professional activities. The research might create an awareness of the existence of OPC amongst the respective stakeholders. In addition, knowledge of OPC may have career management implications for professionals.

\section{Final thoughts}

OPC seems to be a phenomenon that is also prevalent in the profession of IP, and more specifically, amongst professionals employed in organisations. An inability to balance and manage dissimilar expectations may necessitate professionals to align with organisational aspirations and practices whilst negating professional standards. Considering the existence of OPC and the measurement thereof amongst industrial psychologists, it is important that the dynamics regarding this phenomenon are researched to a greater extent in the profession. This may provide insight not only into the primary contributing factors, but also into the professionals' personal experiences of and responses to OPC. In doing so, the phenomenon and implications thereof may be comprehended. This research suggests that OPC may be measured by means of quantitative research instruments and, based on the results, it provides general guidelines for managing and mitigating the effects of OPC on professionals and their practice.

\section{Acknowledgements}

The authors acknowledge and thank Adam Martin for creating the electronic questionnaire and capturing the data in the online responses, the Society of Industrial Psychology of South Africa (SIOPSA) for their financial support, Carly Massimiani for her support and assistance in distributing the electronic link of the survey to delegates, and Jacqueline de Vos for her editorial assistance in tending to the technical details and language of the article.

\section{Competing interests}

The authors declare that they have no financial or personal relationship(s) which may have inappropriately influenced them in writing this paper.

\section{Authors' contributions}

C.L. (University of Johannesburg) contributed towards 50\% of the article, whereas L.J.v.V. (University of Johannesburg) and R.E. (University of Johannesburg) each contributed 25\% towards the article.

L.J.vV. (University of Johannesburg) primarily contributed towards compiling and advising on the content of the literature, the research question, the design of the measurement instrument and the discussion section.

R.E. (University of Johannesburg) contributed with regard to the development of the measurement instrument, advising on the methodology section, and assisted in statistically analysing data gathered and interpreting the results.

\section{References}

Alexandra, A., \& Miller, S. (2003). Needs, moral self-consciousness, and professional roles. In J. Rowan \& S. Zinaich, Jr. (Eds.), Ethics for the professions, (pp. 134-140). Belmont, CA: Wadsworth Thomson Learning.

Banks, S. (2006). Ethics and values in social work. (3rd edn.). New York: Palgrave Macmillan.

Barry, B.E., \& Ohland, M.W. (2009). Applied ethics in the engineering, health, business, and law professions: A comparison. Journal of Engineering Education, 98(4), 377-388.

Billings, J.S. (1981). Hierarchy and community. In R.B. Purtilo \& C.K. Cassel (Eds.), Ethical dimensions in the health profession, (pp. 163-174). Philadelphia, PA: W.B. Saunders.

Borden, S.L., \& Pritchard, M.S. (2001). Conflict in interest in journalism. In M. Davis \& A. Stark (Eds.), Conflict of interest in the profession, (pp. 73-91). New York: Oxford.

Bowen, P., Pearl, R., \& Akintoye, A. (2007). Professional ethics in the South African construction industry. Building, Research \& Information, 35(2), 198-205. http:// dx.doi.org/10.1080/09613210600980267

Brandsen, T. (2009). Civicness in Organizations: A reflection on the relationship between professionals and managers. Voluntas: International Journal of Voluntary and Nonprofit Organizations, 20(3), 260-273. http://dx.doi.org/10.1007/s11266009-9090-3

Brierley, J.A., \& Cowton, C.J. (2000). Putting meta-analysis to work: Accountants' organizational-professional conflict. Journal of Business Ethics, 24(4), 343-353. http://dx.doi.org/10.1023/A:1006184625019

Brooks, L.J. (2001). Conflict in interest in the accounting profession. In M. Davis \& A Stark (Eds.), Conflict of interest in the profession, (pp. 92-111). New York: Oxford.

Cooper, D.R., \& Schindler, P.S. (2008). Business research methods. (10th edn.). New York: McGraw-Hill.

Finley, A.P., Mueller, C.W., \& Gurney, C.A. (2004). Organizational and professional commitment in professional and non-professional organizations: The case of nurse doctorates. In K.T. Leicht (Ed.), Research in social stratification and mobility, Volume 20, (pp. 325-358). Oxford, UK: Elsevier.

Frankel, M.S. (1989). Professional codes: Why, how and with what impact? Journal of Business Ethics, 8(2), 109-115. http://dx.doi.org/10.1007/BF00382575

Gamage, D. (2006). Profession development for leaders and managers of selfgoverning schools. Dordrecht, The Netherlands: Springer. http://dx.doi. org/10.1007/1-4020-4929-3

Gendron, Y., Suddaby, R., \& Lam, H. (2006). An examination of the ethical commitment of professional accountants to auditor independence. Journal of Business Ethics, 64(2), 169-193. http://dx.doi.org/10.1007/s10551-005-3095-7

Gravetter, F.J., \& Forzano, L.B. (2009). Research methods for the behavioural sciences. (3rd edn.). Belmont, CA: Wadsworth.

Gunz, S., \& Gunz, H. (2008). Ethical decision making and the employed lawyer. Journa of Business Ethics, 81(4), 927-944. http://dx.doi.org/10.1007/s10551-007-9558-2

Gunz, S., McCutcheon, J., \& Reynolds, F. (2009). Independence, conflict of interest and the actuarial profession. Journal of Business Ethics, 89(1), 77-89. http://dx.doi. org/10.1007/s10551-008-9985-8

Hair, J.F., Black, W.C., Babin, B.J., Anderson, R.E., \& Tatham, R.L. (2006). Multivariate data analysis. (6th edn.). Upper Saddle River, NJ: Pearson Prentice Hall. 
Harries-Jenkins, G. (1970). Professionals in organizations. In J.A. Jackson (Ed.) Sociological studies 3: Professions and professionalization, (pp. 51-107). London, UK: Cambridge.

Harshman, E.M., Gilsinan, J.F., Fisher, J.E., \& Yeager, F.C. (2005). Professional ethics in a virtual world: The impact of the internet on traditional notions of professionalism. Journal of Business Ethics, 58(1-3), 227-236. http://dx.doi.org/10.1007/s10551005-1417-4

Higgs-Kleyn, N., \& Kapelianis, D. (1999). The role of professional codes in regulating ethical conduct. Journal of Business Ethics, 19(4), 363-374. http://dx.doi. org/10.1023/A:1005899517191

Jespersen, P.K., Nielsen, L.M., \& Sognstrup, H. (2002). Professions, institutional dynamics, and new public management in the Danish hospital field. International Journal of Public Administration, 25(12), 1555-1574. http://dx.doi.org/10.1081/ PAD-120014261

Kahn, J.H. (2006). Factor analysis in counselling psychology research, training, and practice: Principles, advances, and applications. The Counseling Psychologist, 34(5), 684-718. http://dx.doi.org/10.1177/0011000006286347

Keith-Spiegel, P., \& Koocher, G.P. (1985). Ethics in psychology: Professional standards and cases. Hillsdale, NJ: Random House.

Kerlinger, F.N., \& Lee, H.B. (2000). Foundations of behavioural research. (4th edn.). Belmont, CA: Wadsworth Thomson Learning.

KovacsBurns, K. (2005, October). Non-experimental research designs. Paper presented at Nursing 503 workshop, Edmonton, AB.

Leedy, P.D., \& Ormond, J.E. (2010). Practical research: Planning and design. (9th edn.) Upper Saddle River, NJ: Pearson Education.

Lefkowitz, J. (2003). Ethics and values in industrial-organizational psychology Mahwah, NJ: Lawrence Erlbaum Associates.

Mannheim, K. (1981). What is a profession? In R.B. Purtilo \& C.K. Cassel (Eds.), Ethical dimensions in the health profession, (pp. 18-24). Philadelphia, PA: W.B. Saunders.

Pallant, J. (2007). SPSS: Survival manual. (3rd edn.). Berkshire, UK: McGraw Hill.
Peel, D. (2005). Dual professionalism: Facing the challenges of continuing professional development in the workplace? Reflective Practice, 6(1), 123-140. http://dx.doi. org/10.1080/1462394042000326851

Pettifor, J.L., Sinclair, C., \& Strong, T. (2005). The role of dialogue in defining ethical principles: The Canadian code of ethics for psychologists. Journal of Constructivist Psychology, 18(2), 183-197. http://dx.doi.org/10.1080/10720530590914833

Sehested, K. (2002). How new public management reforms challenge the roles of professionals. International Journal of Public Administration, 25(12), 1513-1537. http://dx.doi.org/10.1081/PAD-120014259

Shafer, W.E. (2002). Ethical pressure, organizational-professional conflict, and related work outcomes among management accountants. Journal of Business Ethics, $38(3), 263-275$

Shafer, W.E. (2009). Ethical climate, organizational-professional conflict and organizational commitment: A study of Chinese auditors. Accounting Auditing \& Accountability Journal, 22(7), 1087-1110. http://dx.doi. org/10.1108/09513570910987385

Shafer, W.E., Park, L.J., \& Liao, W.M. (2002). Professionalism, organizationalprofessional conflict and work outcomes. Accounting, Auditing \& Accountability Journal, 15(1), 46-68. http://dx.doi.org/10.1108/09513570210418888

Siu, N.Y.M., \& Lam, K.J. (2009). A comparative study of ethical perceptions of managers and non-managers. Journal of Business Ethics, 88(1), 167-183. http://dx.doi. org/10.1007/s10551-008-9824-y

SPSS. (2010). PASW Statistics 18.0.1. Chicago, IL: SPSS Inc.

Van Vuuren, L.J. (2006, November 8). Industrial psychology: Goodness of fit? Fit for Goodness? Inaugural address, Johannesburg: University of Johannesburg.

Voskuijl, O., \& Evers, A. (2007). Tension between the prescriptive and descriptive ethics of psychologists. Journal of Business Ethics, 72(3), 279-291. http://dx.doi. org/10.1007/s10551-006-9170-x

Yu, K., Lee, S., \& Lee, S.M. (2007). Counselors' collective self-esteem mediates job dissatisfaction and client relationships. Journal of Employment Counselling, 44(4) 163-173. http://dx.doi.org/10.1002/j.2161-1920.2007.tb00035.x 